almost invisible lesions in glands that have been taken as suspicious. It consists in dehydrating the cut surface of the gland either by freezing or by sprinkling with sodium chloride. The dehydration is more complete at the places where the gland has remained sound than at those in which tubercles are being formed. On a number of occasions I have demonstrated in this way, in glands obtained from my own experimental cattle which I scaiccly suspected, or in glands sent to me as sound from animals that had reactcd to tuberculin, very small nodules or areas of induration in the cortical zone which histological examination and inoculation into guinea-pigs have always shown to be of a tuberculous nature. But in some cases glands affected with occult tuberculosis show nothing to excite suspicion; only by inoculation into guinea-pigs can their condition be detected, and in practice one cannot undertake to test them in that way. But it is well to be always mindful of their existence, and by way of conclusion I cannot do better than quote the opinion of MM. Arloing and Thévenot with regard to the disagreements between the indications afforded respectively by experimental diagnosis and by postmortem examination: "The number will be considerably lessened if one looks for histological alterations, and particularly for the presence of bacilli, in making a post-mortem examination." 1

\title{
THE ERADICATION OF GLANDERS IN BIRMINGHAM.
}

\section{By John Malcolm, F.R.C.V.S., Municipal Veterinary Officer, Birmingham.}

As the Board of Agriculture's returns do not reveal any very marked diminution in the prevalence of glanders under the Glanders or Farcy Order of 1907, which came into force on Ist January 1908, a brief record of the entirely successful application of the Order in Birmingham may be of some interest.

Until last year glanders had existed in Birmingham in a greater or less degree continuously for many years, all efforts under the old Order to eradicate it having proved ineffectual. This, no doubt, was partly due to the failure to detect without mallein latent cases in those studs whose owners would not consent to submit their horses to a general test without compensation for reacters, and partly to the frequent introduction of the disease by cast horses from infected studs in London and elsewhere. In this connection it is of some interest to record that the disease was first introduced into two of our large studs, which were responsible for more than half the cases certified in Birmingham last year, by horses with latent disease 
purchased at the dispersal of London studs subsequent to the introduction of motors. Several consignments of such cast horses IIere sent to Birmingham and sold by public auction, and there is no doubt that many cases were due to the introduction of the clisease in the latent stage by these horses; similarly, there is no doubt that many horses sold from infected studs in Birmingham and district disseminated the disease in the surrounding country.

Some years ago our authorities were so anxious to free the City from the disease that for a time, in the hope of eradicating it, they voluntarily gave the owners compensation to the extent of half the value of the horses condemned; but this proved so costly and revealed so many cases (not a few of which were in horses recently brought to the City from outside districts in which no such compensation was paid) that the authorities soon discontinued their voluntary contributions, and resolved not to revert to compensation until the law made it obligatory on all authorities.

Some idea of the former extent and the continued prevalence of the disease from year to year in Birmingham is obtained from the returns for the years $1907-06-05-04$, when there were certified fortyeight, thirty-three, twenty-five, and thirty-four cases respectively. Under the new Order Ioo cases were certified in the year Igos; ninety-four of these were latent. It will be seen from the monthly returns that the application of the new Order during the first three months nearly eradicated the disease. Subsequent to this only five cases occurred, and from 26th September 1908 to the present time, 3 Ist May I909, there has been no case or suspected case of the disease in Birmingham. The actual monthly returns of cases certified in 1908 were as follow':-

\begin{tabular}{|c|c|c|c|c|}
\hline January & . 28 & May. & - & September \\
\hline February & 55 & June & 2 & October \\
\hline March & 12 & July & - & November \\
\hline April & I & August & - & December \\
\hline
\end{tabular}

Clearly so far as Birmingham is concerned the Glanders or Farcy Order of Igo7 has been an unqualified success. Under it in nine months we have succeeded in eradicating the disease, and thus, in a relatively short period, secured a result which a long continued effort failed to effect under the old Order. Fortunately, owing to the introduction of generous compensation and mallein diagnosis, comparatively few horses with latent glanders are now sold, and there is therefore much less risk of the disease being spread than formerly ; as a consequence we have good grounds for hoping that our present freedom from glanders will be maintained.

Birmingham horse owners and their veterinary surgeons welcomed the 1907 Order, and freely rendered all the assistance in their power to the Local Authority in the attempt to stamp out the disease. Partly to this voluntary assistance, but mainly to the wide interpretation of what constitutes suspected or in-contact horses, the rapid success of exterminating the disease under the new Order is to be attributed. Wherever the disease was detected all the horses in the stud were 
deemed in-contact. All were first valued and then tested. The reacters were of course killed, any doubtful reacters tested a second time, and subsequently the whole stud re-tested. The result has been eminently satisfactory. In no instance has a non-glandered horse been killed, and in no stud is there any suspicion of a case having been left undetected.

The revelations by the mallein test clearly showed the necessity of regarding all the horses in infected studs as suspected or in-contact horses. The infected cases were irregularly distributed throughout the stables, and no horse in any stable in an infected yard could be considered free until proved so by the mallein test. Whether this widespread distribution of the infected cases was due to the use of a common water trough at each yard could not be conclusively proved, but the probability of this was not to be disregarded, and the common water trough was consequently discontinued in all cases.

In eradicating glanders in Birmingham we have had an excellent opportunity of observing the great diagnostic value of mallein. Of the Ioo cases certified last year ninety-four were diagnosed solely by mallein, and in every one of these cases the post-mortem verified the accuracy of the diagnosis. Except in one or two cases each postmortem examination was made in the presence of the horse-owner's veterinary surgeon, and it is gratifying to be able to record that in no single instance did any veterinary surgeon deem it necessary to question the result. Fvery case destroyed presented more or less evidence of glanders lesions in the lungs. In only one case did the reaction to mallein appear to be at fault. This was in a horse affected with advanced glanders pneumonia, in which there was practically little or no local or thermal reaction to mallein. In this case there was, however, manifest chronic disease of the lungs, and as the subject was a worn out valueless animal, standing in an infected stable, it was deemed essential to have it slaughtered. This was done, and the post-mortem revealed extensive glanders lesions in the lungs. As a rule, in the few doubtful reacters, the second test was either definitely positive or negative, but in one or two instances the doubt was not entirely removed by that test, and a third was deemed necessary. In these horses the reaction at the third test was so decisively negative as to warrant their being declared free. Whether in these instances the doubtful reaction at first was evidence of some slight incipient infection, from which the patient speedily recovered, or of some other unexplained cause it is impossible to say.

The cost to the City, considering the number of horses destroyed and the result attained, has been comparatively small. The total payment for compensation has been only $£ 644$, or an average of E6, 8s. od. for each horse condemned.

Although the Glanders or Farcy Order of 1907 has not been instrumental in effecting so rapid and striking results in the country senerally as it has in Birmingham, there are yet good grounds for believing that real progress is being made, and we confidently anticipate early proof of this in the Board of Agriculture's returns.

The whole of our experience in dealing with the disease under the I 907 Order has verified the conviction that wherever a sufficiently wide view of what is meant by suspected or in-contact horses is taken 
and acted upon, and where no doubtful reacter is passed as free, a very gratifying result will soon be achieved in any affected stud, and the cost will be less in the end than where inadequate or restricted interpretation of what is meant by in-contact horses is accepted.

\title{
THE EMPLOYMENT OF IODINE IN PNEUMONIA.
}

\author{
By A. C. NEwsom, Major, A.V.C.
}

IN an article on Pneumonia and Pleurisy by the present DirectorGeneral, A.V.S., published in Nos. I and 2, Vol. X., of the Journal of Comparative Pathology and Therapeutics, a suggestion is made as to the possible value of iodine in the treatment of these diseases. With a view to testing this point all cases admitted for treatment to the S.V. Hospital, Woolwich, suffering from these affections of the chest, from 3oth April 1907 to I 5 th December 1908, were submitted to a routine treatment as detailed briefly hereunder. Forty cases were treated during this time, of which four died.

Routine Treatment.-Iodine was administered in doses of I drachm in bolus twice daily from the time diagnosis was made till convalescence was established, or till symptoms of iodism appeared. Where the condition suggested the necessity of stimulants, ether $j_{11}$ drachm doses was given hypodermically.

In seven cases (Nos. 3, 5, 9, I6, 3I, 35, and 38) symptoms of iodism were noticed, as evidenced by diminished appetite, disinclination to drink, a varying degree of skin eruption, and a slight mucopurulent discharge from the eyes. On the appearance of these symptoms the administration of the drug was at once discontinued, but otherwise it was given till convalescence was established.

The shortest period in which symptoms of iodism were observed was in Case 9, when they appeared in six days. On the other hand, Case 6 received the drug for twenty-three days and Case i 8 for thirty days without exhibiting any adverse symptoms.

It appears justifiable to conclude from this series of cases that iodine is well tolerated and can be given in $\mathrm{I}$ drachm doses without fear of harm.

I am personally satisfied that the cases did better than under any other method of treatment which I have employed myself or seen carried out at the hands of others. 